\title{
Splenectomy in Idiopathic Thrombocytopenic Purpura : A Clinical Experience
}

\author{
$b y$
}

INDRO ZAENI, SUKARDI, BAMBANG. P., NETTY R.H.T. and S. UNTARIO

(From the Department of Child Health, Medical Faculty Airlangga University/Dr. Soetomo Hospiral, Surabaya)

\begin{abstract}
Since 1979 until 1987 there were 4 idiophatic thrombocytopenic purpura (ITP) cases who had undergone splenectomy, consisting of 2 males and 2 females. All patients had been treated with prednisone prior to splenectomy, 2 patients received additional cytostatics. The course of the disease prior to spleneciomy had been followed in a period of time, varying from 2,5 to 8 years. The effect of treatment was not very statisfying, as both clinical and laboratory reccurrence often happened.

Post spelectomy, the administration of prednisone in l case was stopped immediately, in 2 cases it was stopped after 8 months and in 1 case it was continued. After more than 5 years follow up, 3 cases showed excellent clinical and laboratory findings, while 1 case failed.
\end{abstract}

\section{Introduction}

Idiopathic thrombocyopenic purpura (ITP) is a disorder of unknown etiology and pathogenesis. ITP in childhood is usually a brief, self limiting disease with an excellent prognosis for spontaneous and complete remission. Nevertheless 7 to 10 percent of these children fail to achieve sustained remission. (Carpenter et al., 1959; Ramos et al., 1978; Weinblatt and

\section{Ortega, 1982).}

Platelet agglutination and complement fixing antibodies have been found to be present in a large proportion of patients suffering from ITP. The spleen may then be implicated in the genesis of the clinical entity, as a source of antibody production, the major sequestering agent for the sensitized platelets, or both. The spleen may 
also be implicated in the genesis of this tomy, corticosteroids, platelets transfusion disease by causing a production defect in and immunosupressive agents. Splenecplatelets. This is evident by the frequent tomy is the oldest, firstly proposed and findings of immature megakaryocytes in performed in 1916, and is still considered the bone marrow.

This may, however, merely represent a "shift to the left"' in response to increased destruction of platelets. It is very true that the spleen is the major sequestering site for platelets in this clinical entity (Block et al., 1966).

The treatment of ITP in childhood, especialy of chronic ITP, has been a matter of controversy in recent years (Wilde et al., 1967; Simon et al., 1975).

There are four modalities available for treatment of chronic ITP i.e.: splenec-

by many experts as the treatment of choice

(Orringer et al., 1970; Bussel et al., 1983).

The arguments in favor of splenectomy emphasize the high of permanent remis-

sion, with figures as high as 80 percent.

(Orringer et al., 1970; Mc Millan, 1981),

but according to others the permanent

remission rate is only 50 to 60 percent (Wilde et al., 1967).

The purpose of this paper is to report the clinical experience of the efficacy of splenectomy for chronic ITP in our patients.

\section{Report of Cases}

In the past 8 years (from 1979) we had Dr. Soetomo Hospital. The details of the experienced only 4 cases of splenectomy in four patients are recorded in table 1. ITP, in the Child Health Department,

Table 1 : Symptoms and signs

\begin{tabular}{|c|c|c|c|c|c|}
\hline & & Case I & Case II & Case III & Case IV \\
\hline A g e & : & 7 years & 11 years & 3 years & 3.5 years \\
\hline S e $x$ & $:$ & malc & remale & malc & femalc \\
\hline Symptoms & : & epistaxis & $\begin{array}{l}\text { gingival } \\
\text { blecding }\end{array}$ & petechiae & hesnatoma \\
\hline
\end{tabular}

S ig n

- Ecchymosis

- Petechiae

- Liver \& Spleen enlargment

- Lymph node enlargment

Other diseases

Drug ingestion
There were 2 males and 2 females, and their ages ranged from 3 years to 11 years. Epistaxis, bleeding of the gingiva, petechiae and ecchymosis or hematoma were the most common symptoms that occurred in our patients. On physical examination only

ecchymosis ( 3 cases) and petechiae ( 3 cases) were found. Other signs and symptoms were not present.

The detail of the laboratory findings are recorded in table 2 and 3.

Table 2 : Blood examination

\begin{tabular}{|c|c|c|c|c|c|}
\hline & & Case I & Case II & Case III & Case IV \\
\hline Hemoglobin ( $g / d l)$ & : & 10 & 11.1 & 10 & 10.7 \\
\hline Erythrocyte & & 4110000 & 4340000 & 4600000 & 3120000 \\
\hline Leucocyte & : & 10.400 & 16.800 & 13.800 & 6.900 \\
\hline Platelet & : & 31.000 & $(-)$ & $(-)$ & 3.000 \\
\hline \multicolumn{6}{|l|}{ Diff. count } \\
\hline Eosinophil & : & - & - & 2 & 7 \\
\hline Basophil & & - & - & - & - \\
\hline Stab & & 1 & - & 3 & 2 \\
\hline Segment & & 65 & 40 & 55 & 23 \\
\hline Lymphocyte & & 34 & 59 & 37 & 65 \\
\hline Monocyte & & - & 1 & 3 & 3 \\
\hline
\end{tabular}

No anemia was found in all cases. The had severe thrombocytopenia (platelets platelet count was decreased and 2 patients were not performed in the blood smears). 
Table 3 : Bone marrow examination and L.E. cell

\begin{tabular}{|c|c|c|c|c|c|}
\hline & & Case I & Case II & Case III & Case IV \\
\hline Bone marrow & : & & & & \\
\hline - Cellularity & : & & & & \\
\hline - Eryth. system & & Hormal & normal & hyper & normal \\
\hline & ; & good & moderate & increased & good \\
\hline - Gran. system & : & good & moderate & $\begin{array}{c}\text { increased, } \\
\text { Eo }>\end{array}$ & $\begin{array}{l}\text { good, } \\
\text { Eo }>\end{array}$ \\
\hline - Megakar. system & $:$ & suffic. & suffic. & increased & increased \\
\hline L.E. cell & : & neg. & neg. & neg. & neg. \\
\hline
\end{tabular}

Bone marrow examination revealed normocellularity in 3 cases and hypercellularity in one. No abnormalities were found in the erythropoietic and granulopoietic systems. The megakaryocytes were sufficient in increased. L.E cells were others they cases (table 3 ).

Table 4 : Treatment of cases before splenectom

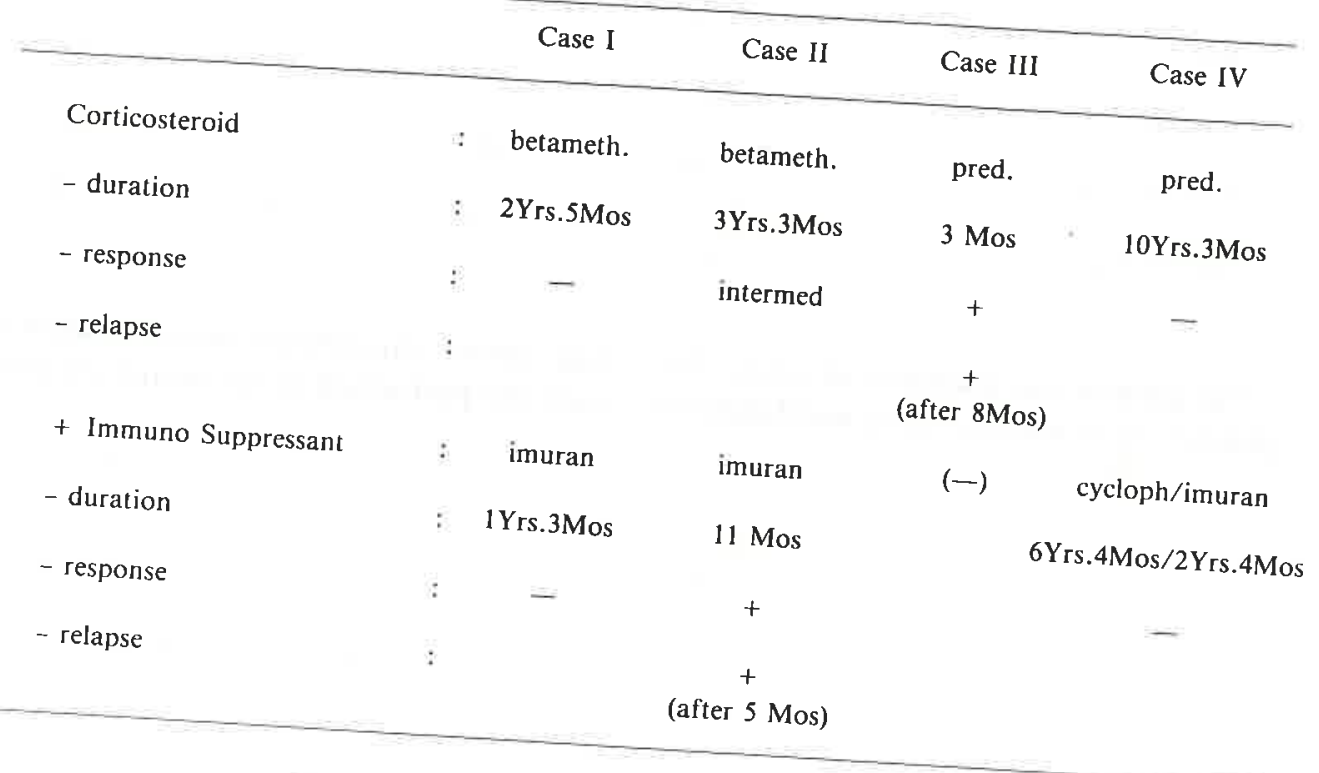

Before splenectomy all patients received corticosteroid (betamethasone or prednisone) in a period of time, varying from 3 mos to 10 years 3 mos (table 4 ) response were noted in 2 cases (case 1 . No case IV), I patient had (case I and response, and only 1 patient had esponse though then, after 8 months without corticosteroid administration the

patient showed signs of relapse.

Only 1 patient had not received immuno suppressant (case IV) while the others got immuno supressant administration varying from 11 months to 6 years. Response to immuno supressant was corded only in one patient (case II) with good response though relapse then. occurred after 5 months (table 4).

Table 5 : Preoperation of splenectomy

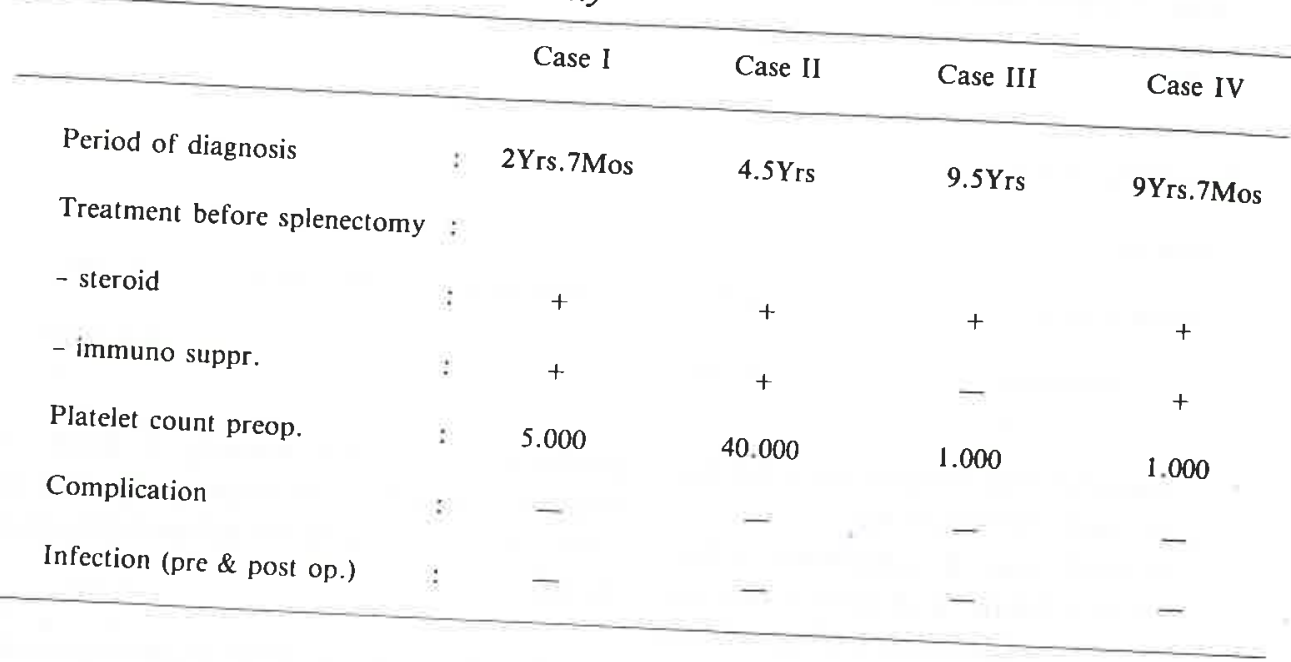

The diagnosis of ITP was established after a period of time, varying from 2 years 7 months to 9 years 7 months. The platelet count before splenectomy was low especially after after splenectomy (table 5). in case III and IV. No infection or other 
Table $6:$ The course of the disease after splenectomy

\begin{tabular}{|c|c|c|c|c|c|}
\hline & & Case I & Case II & Case III & Case IV \\
\hline Corticosteroid & : & stopped & $\begin{array}{l}\text { continued } \\
\text { (15 Mos) }\end{array}$ & $\begin{array}{l}\text { continued } \\
\text { (9 Mos) }\end{array}$ & continued \\
\hline Immuno supressant & : & stopped & $\begin{array}{l}\text { continued } \\
\text { (16 Mos) }\end{array}$ & - & continued \\
\hline Response to splenectomy & : & + & + & + & - \\
\hline Period of platelet increase & : & I week & I Mo & $2 \operatorname{Mos}$ & - \\
\hline Relapse & : & $\stackrel{+}{\stackrel{+}{\text { (after }} 4 \mathrm{Yrs} \text { ) }}$ & $\stackrel{+}{+}$ & - & - \\
\hline Reccurrent remission & : & + & + & & \\
\hline Follow up & : & & & & \\
\hline - period of time & : & $4 \mathrm{Yrs}$ & $8 \mathrm{Yrs} .4 \mathrm{Mos}$ & 4 Yrs.9Mos & 4 Yrs.10Mos \\
\hline - clinic. appearence & : & good & good & good & petechiaes \\
\hline
\end{tabular}

The course of the diseases post splenectomy had been followed up.

Corticosteroid was discontinued immediately, after 15 mos, and after 9 mos for case I, II, III, respectively, while in case IV corticosteroid was administered continously. Immuno supressive agent was administered continously only in case IV. Respons to splenectomy was recorded in case I, II, III with good responses and

performed in time namely 1 week, 1 month, and 2 months respectively. But in case IV no response to splenectomy was noted.

In case I \& II, relapse after 4 years occured, though followed by immediate reccurent remission with a good condition (table 6) The platelet count before and after splenectomy is recorded in table 7.

Table 7 : Platelet count before and after splenectomy

\begin{tabular}{cccc}
\hline Case & \multicolumn{2}{c}{$\begin{array}{c}\text { Mean platelet count }(\times 1000) \\
\text { After splenec. }\end{array}$} & $\begin{array}{c}\text { Significancy }: \mathrm{p} \\
(\mathrm{S} / \mathrm{NS})\end{array}$ \\
\hline I & $23 \pm 6$ & $163 \pm 89$ & $\mathrm{p}:<0.001$ ( S ) \\
II & $63 \pm 27.6$ & $103 \pm 39.7$ & $\mathrm{p}:<0.01$ (S) \\
III & $53 \pm 44$ & $168 \pm 5.4$ & $\mathrm{p}:<0.001$ (S) \\
IV & $10 \pm 11$ & $7 \pm 7.3$ & $\mathrm{p}:>0.05$ (NS) \\
\hline
\end{tabular}

After splenectomy, mean platelet count decreased, but not significantly different increased significantly in cases I, II and than before splenectomy.

III. In case IV the mean platelet count

\section{Discussion}

Chronic idiopathic thrombocytopenic become sensitized and develop isoantipurpura (ITP) is a syndrome of persistent bodies to the foreign platelets.

thrombocytopenia secondary to an increased The use of immunosuppressive agent in the platelet destruction by the reticulo endo- treatment of chronic ITP not yet achieved thelial system, presumably caused by anti- wide acceptance (Orringer et al., 1970). It platelet antibodies (Weinblatt and Ortega, therefore appears to us that splenectomy 1982). According to Bussel et al. (1983), the is the preferred treatment in chronic ITP. syndrome at least lasts for 6 months, such as our cases. Some authors recomaccompanied by an increase of megakaryo- mended splenectomy to be performed in cytes in the bone marrow and frequently patients with ITP that persists 6 to 12 by an elevated platelet associated immuno- months (Weinblatt and Ortega, 1982; Wilde globulin G (PAIgG). In our patients, et al., 1967; Ramos et al., 1978). In practice

thrombocytopenia had been recorded for though it is recommended to operate after more the 6 months.

The modalities of therapy for chronic thrombocytopenic purpura include the use of steroid, platelet transfusion or immunosuppressive agents and splenectomy. The results of steroid therapy vary and in reported series remissions range from 15 to 60 per cent. From the literature it appears that the percentage of remission at least in part, depend on the steroid dosage. Unfortunately, the adverse effect of longterm corticosteroid therapy represents the major argument against sustained usage of this drug.

The use of platelet transfusion seems 10 be of some benefit in a life threatening emergency, although evidence of their usefulness is sparse. A major sole cannot be ascribed to these transfusion for several reasons: (1) Heterologous platelets have a markedly shortened life span just as do autologous platelets. (2) The expense in preparing platelet concentration for use on a long term basis is prohibitive. (3) Patients receiving platelet transfusions quickly one year of illness (Schulman, 1964). According 10 Mc. Millan (1981), splenectomy should be postponed if possible until at least the age of six years, such as in our cases.

In patients with ITP that are refractory to corticosteroid, corticosteroid therapy should be continued before surgery, and in patients with a good response it should be tapered off rapidly and discontinued then after surgery (Mc. Millan, 1981). In our cases corticosteroid was continued in one patient, and cliscontinued in 3 patients (case I, II, III) immediately, after 15 Mos and 9 Mos post splenectomy, respectively.

Following splenectomy the platelet rise usually begins within the first 24 hours and it occasionaly will exceed one to two million percubic milimeter at the end of four to five days (Block et al., 1966). According to Mc. Millan (1981), improvement may occur within hours and peaks achieved within two weeks. If relapse occurs it is usually note in the first six weeks. In our case improvement was 
recorded in 3 cases (case I, II, III), and occurred after 1 week, 1 month and 2 months, respectively. Relapse occured until 4 years post splenectomy (case I, II) and afterwards reccurent remission occurred again. The improvement of platelet count in our cases was recorded significantly in 3 cases, but in one case the platelet count decreased post splenectomy though not significantly different.

Post operative (splenectomy) complication outlined, as subdiaphragmatic abscess, wound infection, septicemia, pneumonia, post operative hemorrhage and thrombocytosis (Wilde et al., 1967) were not at all found in our cases.

\section{Conclusion}

(1) Splenectomy is recommended in chronic ITP, especially when this disease is refractory to the medical approach.
(2) With close observation during splenectomy preparation, the post splenectomy complication could be prevented.

\section{REFERENCES}

1. BLOCK, G.E.; EVANS, R.; ZAJTCHUK, R.: Splenectomy for idiopathic thrombocytopenic purpura. Archs Surg. 92 : 484-489 (1966).

2. BUSSEL, J.B.; KIMBERLY, R.P.; INMAN, R.D.; SCHULMAN, I.; RUNDLES, C.C.; CHEUNG, N.; SMITHWICK, E.M.; O'MALLEY, J.; BARANDUN, S.; HILGARTNER MW.: Intravenous gammaglobulin treatment of chronic idiopathic thrombocytopenic purpura. Blood. 62 : 480-486, (1983).

3. CARPENTER, A.F.; WINTROBE, M.W.; FULLER, E.A.; HAUT, A.; CARTWRIGHT, G.E.: Treatment of idiopathic thrombocytopenic purpura. J.Am.med.Ass. 171 : 1911-1916 (1959).

4. Mc. MILLAN, R.: Chronic idiopathic thrombocytopenic purpura. New Engl.J.Med. 304 : 1135-II46 (1981).

5. ORRINGER, E.; LEWIS, M.; SILVERBERG, J.; ROSENBACH, L.: Splenectomy in chronic thrombocytopenic purpura. J. Chron. Dis.23 : 117-122 (1970).

6. RAMOS, M.E.G.; NEWMAN, A.J.; GROSS, S.: Chronic thrombocytopenia in childhood. J. Pediat. 92 : 584-586 (1978).

7. SCHULMAN, I.: Diagnosis and treatment: Management of idiopathic thrombocytopenic Purpura. Pediatrics (1964).

8. SIMONS, S.M.; MAIN, C.A.; YAISH, H.M.; RUTZKY, J.: Idiopathic thrombocytopenic purpura in children. J. Pediat. $87: 16-22$ (1975).

9. WEINBLATT, M.E.; ORTEGA, J.A.: Steroid responsiveness. Am. J. Dis. Child. 136 : 1064- 1066 (1982).

10. WILDE, R.C.; ELLIS, L.D.; COOPER, W.M.: Splenectomy for chronic idiopathic thrombocylopenic purpura. Archs Surg. 95 : 344-350 (1967). 